\title{
Xp22.3 microdeletion syndrome
}

INSERM

\section{Source}

INSERM. (1999). Orphanet: an online rare disease and orphan drug data base. Xp22.3 microdeletion syndrome. ORPHA:1643

Xp22.3 microdeletion syndrome is a microdeletion syndrome resulting from a partial deletion of the chromosome X. Phenotype is highly variable (depending on length of deletion), but is mainly characterized by $\mathrm{X}$ linked ichthyosis, mild-moderate intellectual deficit, Kallmann syndrome, short stature, chondrodysplasia punctata and ocular albinism. Epilepsy, attention deficit-hyperactivity disorder, autism and difficulties with social communication can be associated. 